\title{
Epidermal and Melanocitic Tumors in Dogs and Cats: a Review
}

\author{
Daria-Antonia DUMITRAȘ ${ }^{1}$, Sanda ANDREI ${ }^{1 *}$ and Adrian Florin GAL ${ }^{1}$ \\ ${ }^{1}$ Department of Preclinical Sciences, Faculty of Veterinary Medicine. University of Agricultural Sciences \\ and Veterinary Medicine Cluj-Napoca, Romania. \\ *corresponding author: sandrei@usamvcluj.ro
}

Bulletin UASVM Veterinary Medicine 76(2)/2019

Print ISSN 1843-5270; Electronic ISSN 1843-5378

doi:10.15835/buasvmcn-vm:2019.0027

\begin{abstract}
:
Skin is the organ-barrier which assures the isolation and the protection of the organism, but in the same time, it is vulnerable because of its continuous exposure to various environmental factors. Unfortunately, the prevalence of skin cancer in pet animals continues to rise. Several studies have been conducted with the purpose of establishing incidence rates of skin cancer in pets, revealing that regarding dogs, tumors of the skin are the most common, accounting for approximately $30 \%$ of all tumors. Similarly, skin tumors in cats are very often diagnosed, accounting for approximately $25 \%$ of all tumors (Meuten, 2012; Withrow and Vail, 2007).

Considering the importance of deepening the studies related to skin cancer in dogs and cats, this review aims to emphasize the most common types of epidermal and melanocytic neoplastic lesions, highlighting their prevalence, the associated factors, the gross morphology and the histological features.
\end{abstract}

Keywords: skin cancer, dogs, cats

\section{Introduction}

Skin tumors are more frequently diagnosed than tumors located in other organs / tissues because they are most easily observed and because are more often due to the constantly exposure of the skin to various tumor-causing factors. It is well known the complexity and heterogeneity of cutaneous structures, all components of the skin having the potential for developing tumors (Meuten, 2012). According to Withrow and Vail (2007), $20 \%$ to $40 \%$ of skin tumors diagnosed in dogs have malignant behavior, whereas in cats, $50 \%$ to $65 \%$ of skin neoplasia are histologically malignant. According to data published by both Brønden et al. (2010) and Grüntzik et al. (2015), skin tumors were the most frequent type of neoplasia diagnosed, with a percentage of $43 \%$ respectively $37,05 \%$. There is a variation regarding the most common skin tumors in dogs and cats between studies, but the same authors highlighted that purebred animals are twice as likely to develop malignant tumors as crossbreed ones. Future studies on the genetic basis for the higher incidence of certain types of tumors in some breeds and the decreased incidence in others should be performed.

This paper is divided into two main sections. The first section gives a brief overview of epidermal neoplasia in dogs and cats and in the second section presents the malignant melanomas in dogs and cats, emphasizing the prevalence, breed, gender and age predilection.

\section{Epidermal neoplasia in dogs and cats}

The heterogeneity of cutaneous structures may bring difficulties in the classification of the skin tumors. In general, cutaneous neoplastic 
processes have been classified histologically according to the tissue of origin. Epidermal tumors have been further classified on their behavior as benign and malignant. Our aim is to focus on the malignant ones, especially the most frequent diagnosed, due to their ability to invade and distruct the areas of the affected skin and also to metastasize in other organs causing multiple damage in the organism (Baba and Catoi, 2007 2012; Withrow and Vail, 2007).

Squamous cell carcinoma (SCC) is one of the most malignant tumors of the skin, being frequently diagnosed in all domestic animals, in which the tumor cells show keratinocyte differentiation (Goldschmidt et al., 2002; Meuten, 2012; Miller et al., 2013). According to some authors (Morris and Dobson, 2001), SCC is the most common malignant cutaneous tumor in the cat. That is the reason that made us decided to focus on this type of malignant epidermal neoplasia. It may occur in young animals, but it usually affects older individuals, with a peak incidence of 6-13 years of age (Meuten, 2013) in dogs, respectively 9-13 years of age in cats (Goldschmidt et al., 2002). Haziroglu et al. (1989) described a very interesting case of SCC diagnosed in a 4-month-old mixed-breed dog with the lesion located near the ombilicus.

Development of this type of cutaneous tumor has been associated with multiple causal factors, prolonged and repeated exposure to UV light being one of the most frequent incriminated. This is based on the usually preceding by actinic (solar) keratosis and the higher number of cases diagnosed in geographic areas characterized by long periods of intense sun (Gomes et al., 2000; Goldschmidt et al., 2002; Mukaratirwa et al., 2005). As mentioned by Scott et al. (1995) and Miller et al. (2013), SCC in dogs has been associated with several chronic infectious or inflamatory processes such as discoid lupus erythematous or otitis externa. Several studies have been describing the role of Papillomavirus in the development of SCC in dogs (Teifkke et al., 1998) and cats (Munday et al., 2013), in a recent study that has been carried out being found Papillomavirus DNA in 24\% of the samples with SCC (Nespeca et al., 2006). On the other hand, some authors (Miller et al., 2013) have expressed doudbts regarding the relationship between Papillomavirus and SCC. Callan et al. (2005) has mentioned that cigarete smoke and different substances contained by the anti-fleas colar as being also involved in the development of SCC, epecially the oral type in the cats. While some authors (Baba and Catoi, 2007) mentioned that regarding dogs, breed does not seem to be a risk factor, several researchers (Goldschmidt et al., 2002; Miller et al., 2013; Nikula et al., 1992) mentioned the predisposition to SCC of breeds with sparsely haired and lightly pigmented skin such as Beagle, Dalmatian, Whippet and Bull terrier, especially if they spend a lot of time in the sun. Bussanich et al. (1987) reported Labrador and Black Caniche dogs to have a higher sensitivity, while Meuten (2012) described Bloodhound, Giant schnauzer, Keeshond, Kerry blue terriers and Bull mastiff breeds to be at risk. In a retrospective review made by Silva-Hidalgo et al. (2015) in Mexico, the authors mentioned a $20 \%$ incidence in SCC in dogs in that area, Bull terriers being the most often affected, with a peak incidence of 2-4 years. Similar to other researchers, these ones described dogs with white coats as being at a higher risk and also the prepuce as the anatomical location most frequent affected by SCC. Regarding cats, no breed or sex predilectioned has been mentioned, but according to Goldschmidt et al. (2002) and Miller et al. (1991), Siamese cats seems to have a decrease risk, most probably due to their hair and skin color. An important fact that has been reported (Miller et al., 2013) is that white cats have a 13 times greater risk of developing SCC than cats of other colors.

Head, limbs, perineum, lips and digits are the areas where SCC most frequently occurs in dogs, but there were also reported cases of SCC located at at the wall of the anal sacs and also in the subcutaneous tissue at the site of prior vaccination with a papillomavirus vaccine (Bregman, 1987). Lascelles et al. (2000) mentions the nasal planum SCC as a possible sequela associated to depigmentation in discoid lupus erythematosus. Nailbed neoplasms are very often reported and they are most probably related to cronic inflamation or repedeat trauma at that level. In their retrospective study on 64 dogs with canine digital tumors, Henry et al. (2005) states that aproximately $75 \%$ of dogs affected by sybungual SCC are large breeds and $70 \%$ of them have black coats. Usualy only one digit it is affected, but same authors anda also Brodzki et al. (2004) mentioned multiple digital SCC in large black dogs as Rottweiler, Standar Poodles, black 
Table 1. Incidence of SCC in different geographical areas

\begin{tabular}{cccc}
\hline \multirow{2}{*}{ Area } & \multicolumn{2}{c}{ Percentage of cases } & \multirow{2}{*}{ Reference } \\
\cline { 2 - 3 } & Cats & Dogs & Miller et al., 1991 \\
\hline USA & 15 & Not mentioned & Brønden et al., 2009 \\
\hline Denmark & Not mentioned & $28 \%$ & Silva-Hidalgo et al, 2015 \\
\hline Mexico & Not mentioned & 20 & Martins et al., 2014 \\
\hline Brazil & 32 & 2.07 & \\
\hline
\end{tabular}

Labradors, giant Schnauzers and German sheperd dogs. Martins and Barros (2014) investigated SCC samples on a period of fifty years and they identified a case of bilateral SCC of the third eyelid in a dog. Also, they mentioned an individual that among the conjunctival SCC, presented other 5 cutaneous sites along the body that had SCC lesions. Same authors reported that 56,2\% $(9 / 16)$ of the cats included in the study presented multiple areas of the head affected. In two of their evaluated cases, they noticed the invasion of the eyeball by SCC originary in the eyelids.

In cats, lesions described most frequently in literature are interesting the head (nose, pinna, eyelids). In a recent study made by da Conceicao et al. (2016) it was described a case of SCC located in the third eyelid of a cat. Very often, more than one site of the head are affected, $30 \%$ of the cats taken into a study being reported to have multiple lesions (Lana et al., 1997). According to Miller et al. (1991) and Ruslander et al. (1997), the lips are less frequently involved than the rest of the head. Usually, lesions are chronic and they are progressing from erythema to superficial dermatitis and then to deep erosions. Primary SCC of the feline digits seems to be rare, the majority of the reported cases have been shown to be secondary to metastasize from pulmonary carcinomas (Gottfried et al., 2000; van der LindeSipman et al., 2000). Also, Scott-Moncrieff et al. (1989) reported a case of digital SCC in a cat that was secondary due to metastasis. In 2000, the same author, conducted a study on 36 cats with subungual SCC. In 2011, van der Linde-Sipman et al., mentioned the diagnosis of 8 individuals with primary digital SCC in a study of a total of 64 cases of subungual SCC in cats.

SCC may manifest as either proliferative or erosive lesions. The most common are the erosive ones, which are strongly invasive, infiltrating in some cases the underlying dermal and even subcutaneous tissue. Although invasive, this type of cancer is not known to metastasize very often to regional limph nodes. However, in some cases, it has been observed an inflammatory reaction of limph nodes due to the ulceration and inflammatory process in the affected area. One of the first changes that can be recognized by the owner is the solar dermatosis (actinic keratosis), most frequently in the areas of skin that lacks pigment. Consequently, erythema an edema can be observed, and most often as the neoplasm invades the skin layers, the surface appears ulcerated. The now ulcerated lesions are evolving, and secondary bacterial infection could be noticed as a purulent exudate on the surface. Subungual SCC is a very aggressive and locally invasive type that arises from the subungual epithelium and can result in bone lysis of the third phalanx. The lesions are ulcerative, hemorrhagic and painful and often can be noticed the fracture or the absence of the nail. SCC lesions of the eyelids are often associated with conjunctivitis and planum nasal neoplasms are associated with sneezing and epistaxis (Withrow and Vail, 2007; Meuten, 2012).

Table 1 compares the incidence of SCC in dogs and cats mentioned in various studies performed in different areas.

Another type of neoplastic transformation of epidermal cells is represented by the multicentric SCC in situ (Bowen's disease), a variation of SCC that is most often diagnosed in cats, rarely in dogs. It was frequently associated with Papillomavirus (Meuten, 2012). There has been some disagreement regarding the role of sunlight exposure; while some authors (Cox et al., 1994; Hansen et al., 2008; Morton et al., 2014) outlined that among the causal factors of Bowen's disease 
UV light must be included, others (Meuten, 2012; Miller et al., 2013) suggest the contrary, by proving that most of the affected individuals have dark hair and the affected areas are very variable.

The age of 12 years was indicated as the average for individuals diagnosed with Bowen's disease. Until now, no breed has been mentioned as being predisposed, but most of the cases described in literature mentioned shorthaired cats with different hair-coat colors. According to Munday et al. (2014), hairless breeds may be predisposed, and the lesions found in these breeds are more severe. Also, it was not established a gender predilection, but it seems that neutered individuals may be more sensitive. An important role in the development of this disease is played by the immunosuppression. Usually, the lesions do not invade through the basement membrane, being confined to the epithelium. Multiple sites can be affected, the trunk, limbs, feet, head and neck being most often described in literature as sites of occurrence. Lesions are usually multiple, irregular, crusty, epilated, painful, hyperpigmented and can be hemorrhagic and some of them become almost verrucous (Baer et al., 1993; Miller et al., 2013). The size of the lesions is variable, from $0.5 \mathrm{~cm}$ to 3 $\mathrm{cm}$ in diameter (Goldschmidt et al., 2002; Meuten, 2012).

Baer et al. (1993) described two histological types of Bowen's disease: an irregular nonhyperkeratotic type and a verrucous hyperkeratotic one. The first type is characterized by severe acanthosis of the epidermis and an irregular surface of the epidermis, while the verrucous lesions show hyperkeratosis and dilatation of the follicular infundibulum and there can be also noticed ortho-keratin spires arising from the follicular ostium. It can be observed the highly variation of the morphology of the neoplastic cells, variation that gives a disorganized appearance to the epidermis. While some cells can be large and have euchromatic nuclei with proeminent nucleoli and a clear or vacuolated eosinophilic cytoplasm, some of them can be small, containing a very small quantity of cytoplasm and hyperchromatic nuclei. Mitotic figures are common as well as hypermelanosis which is frequently noted. The presence of a lichenoid inflamatory infiltrate has been also described (Meuten, 2012; Miller et al., 2013).

\section{Malignant melanomas in dogs and cats}

Melanocytes are mature dendritic cells that have the ability to produce the melanin, pigment which is stored within melanosomes. Melanosomes are transferred to keratinocytes where the melanins contribute to the protection of the skin from the harmful effects of the ultraviolet radiation. Melanocytic tumors are relatively common skin tumors that can have benign or malign behavior, their origin being at the cells that form the melanocytic system.

Melanocytic tumors are lesions that can have benign or malignant behavior, their origin being in the cells that form the melanocytic system. Numerous studies have been carried out related to melanocytic tumors, especially interesting dogs and cats. Malignant melanoma represents the malignant neoplasm of melanocytes. Most of the authors mention that the cutaneous melanocytic tumors in dogs account for approximately 10 to $15 \%$, except Withrow and Vail (2007), who describes that only a 5 to $7 \%$ of the canine skin tumors represents tumors of melanocytes and melanoblasts. Cats are less often affected by this type of cancer, melanocytic tumors representing $0.8-2.7 \%$ of feline skin tumors. It seems that the most frequent affected are the older dogs, average age mentioned in literature being 9 years. Male individuals were mentioned in older articles to be predisposed, but more recent reports do not support those findings. It has been suggested that dog's breed plays an important role regarding the behavior of melanocytic tumors. Withrow and Vail (2013) underlines that approximately $75 \%$ of melanomas diagnosed at Doberman pinscher and Miniature Schnauzer are benign, whereas more than $85 \%$ of melanomas found in Poodles have a malignant behavior. Also, it was highlighted in some reports the predisposition of some breeds such as Schnauzer family, Scottish terriers and Irish setters to develop subungual melanoma (Miller at al., 2013). No sex predilection has been reported. Regarding cats, older ones are also considered to be at a greater risk, with an average age of 10-12 years, but in their case, no gender or breed predilection is yet known. Chamel et al. (2017) investigated 30 cases of non-ocular melanoma in cats and concluded that, contrary of what was already known, the auricular form of melanoma affected younger cats than other forms. 
Most of these tumors arise primarily in areas of haired skin, involving most commonly the head, limbs, digits, scrotum and trunk, animals with dark hair being indicated to present a greater risk. Also, a very common site of melanoma is the oral cavity and mucocutaneous junctions. Intraocular melanoma was most often associated with German sheperd dogs. In this case, the melanoma can be located intraocularly or periocular (Baba and Catoi, 2007). Predilection sites for melanomas in cats are the head and the neck, the lips, eyelids and pinna being the most frequent sites. Is yet unknown the etiology of this type of tumor, but current investigations are shedding some light on the subject, data published in literature suggesting a multifactorial etiology, the hereditary factor being considered the most important one.

It must be stated that the malignant melanoma can be differentiated from benign forms only using the histopathological exam, on gross examination, the lesions being very similar, in both cases. Size, degree of pigmentation and the aspect of the surface are not reliable indicators of malignant potential. On the other hand, the invasion of surrounded tissues and the metastasis via lymphatics to regional lymph nodes, lungs or other organs can be considered specific for malignant types. Histopathologically, melanomas are characterized by atypical melanocytes in sheets, packets, and cords. The majority of malignant melanomas are poorly differentiated. A very important malignancy criterion is represented by the presence of intravascular melanocytes. The mitotic index is variable, so even in some cases of low-grade malignancy, the number of mitosis could be very low, and consequently these criteria could not be decisive when it comes to establish a diagnosis. The presence of giant cells within the neoplastic melanocytes is considered to be another important hint and they are very often noticed in the case of high malignancy melanomas. In a report, there were described five histologic types of feline melanoma: signet-ring, epithelioid, balloon-cell, mixed epithelioid or spindle, and spindle (van der Linde-Sipman et al., 1997).

\section{Conclusion}

Our review has highlighted data about some of the most important skin tumors in dogs and cats, informations that we believe that are important due to their practical character and can represent an important tool for establishing a real and immediate diagnosis and also for making the best treatement choises as well as establishing an accurate prognosis.

Acknowledgments: This research did not receive any specific grant from funding agencies in the public, commercial, or not-for-profit sectors.

\section{References}

1. Baba AI, Catoi C (2007). Comparative Oncology, The Publishing House of the Romanian Academy

2. Baer KE and Helton K (1993). Multicentric squamous cell carcinoma in situ resembling Bowen's disease in cats. Veterinary Pathology, 30: 535-543.

3. Bregman CL, Hirth RS, Sundberg JP and Christensen EF (1987). Cutaneous neoplasms in dogs associated with canine oral papillomavirus vaccine. Veterinary Pathology, 24: 477-487.

4. Brodzki A, Lopuszynski W, Komsta R (2004). Analyses of the treatment of malignant digital neoplasia of dogs: clinical, radiological and histological evaluation. Tierarztliche Umschau, 59: 594-600.

5. Brønden LB, Eriksen T, Kristensen AT (2009). Oral malignant neoplasms and other head and neck neoplasms in Danish dogs- data from Danish Veterinary Cancer Registry. Acta Vet Scand, 51(1): 54.

6. Brønden LB, Nielsen SS, Toft N, Kristensen AT (2010). Data from the Danish veterinary cancer registry of the occurrence and distribution of neoplasms in dogs in Denmark. Veterinary Record, 166(19): 586-590.

7. Bussanich NM, Dolman PJ, Rootman J, Dolman CL (1987). Canine Uveal Melanomas: Series and Literature Review. Journal of The American Animal Hospital Association, 23:415-422.

8. Callan MB, Preziosi D, Mauldin E (2005). Multiple papillomavirus-associated epidermal hamartomas and squamous cell carcinomas in situ in a dog following chronic treatment with prednisone and cyclosporine. Veterinary Dermatology, 16: 338-345.

9. Chamel G, Abadie J, Albaric O, Labrut S, Ponce F, Ibisch C (2017). Non-ocular melanomas in cats: a retrospective study of 30 cases, Journal of Feline Medicine and Surgery, 19:351-357.

10. Cox NH (1994). Body site distribution of Bowen's disese, The British Journal of Dermatology, 130: 790-793.

11. da Conceicao ME, Martins DM, Bertolo PHL, Bezerra DK, da Silva CD, de Aguirra LR, VasconcelosRO, Pereira WLA (2016). Squamous cell carcinoma in third eyelid of cat. Acta Scientiae Veterinariae, 44(Suppl 1): 170.

12. Goldschmidt MH, Hendrick MJ (2002). Tumors of the skin and soft tissues. (4 ${ }^{\text {th }}$ ed.). Ames, Iowa State Press, p. 50-64.

13. Gomes LAM, Ferreira AMR, Almeida LE (2000). Squamous cell carcinoma associated with actinic dermatitis in seven white cats. Feline Practice, 28:14-16.

14. Gottfried SD, Popovitch CA, Goldschmidt MH (2000). Metastatic digital carcinoma in the cat: a retrospective 
study of 36 cats (1992-1998). Journal of The American Animal Hospital Association, 36:501-509.

15. Grüntzik K, Graf R, Hässig M, Welle M, Meier D, Lott G, Erni D, Schenker NS, Guscetti F, Boo G, Axhaunsen K, Fabrikant S, Foljers G, Pospischil A (2008). The Swiss Canine cancer Registry: a retrospective study on the occurrence of tumours in dogs in Switzerland from 1955 to 2008. Journal of Comparative Pathology, 152(2-3): 161-171.

16. Hansen JP, Drake AL, Wailling HW (2008). Bowen's disease: a four-year retrospective review of epidemiology and treatement at a university center, Dermatologic Surgery, 34: 878-883.

17. Haziroglu R, Saglam M (1989). Squamous cell carcinoma in a puppy. Journal of Comparative Pathology, 101:221223.

18. Henry CJ, Brewer WGJr, Whitley EM (2005). Canine digital tumors: a veterinary cooperative oncology group retrospective study of 64 dogs. Journal of Veterinary Internal Medicine, 19:720-724.

19. Lana SE, Ogilvie GK, Withrow SJ (1997). Feline cutaneous squamous cell carcinoma of the nasal planum and the pinnae: 61 cases. Journal of The American Animal Hospital Association, 33:329-332.

20. Lascelles BD, Parry AT, Stidworthy MF (2000). Squamous cell carcinoma of the nasal planum in 17 dogs, Veterinary Record, 147:473-476.

21. Martins TG, Barros CSL (2014). Fifty years in the blink of an eye: a retrospective study of ocular and periocular lesions in domestic animals. Pesquisa Veterinaria Brasileira, 34(12):1215-1222.

22. Meuten DJ (2012). Tumors in Domestic Animals, $5^{\text {th }}$ edition. Iowa, USA.

23. Miller MA, Nelson SL, Turk JR (1991). Cutaneous neoplasia in 340 cats. Veterinary Pathology, 28:389-395.

24. Miller WHJr, Griffin CE, Campbell KL (2013). Muller\&Kirk's Small Animal Dermatology. ( $7^{\text {th }}$ ed.)., Elsevier.

25. Morris J, Dobson J (2001). Small Animal Oncology, Blackwell Science

26. Morton CA, Birnie AJ, Eedy DJ (2014). British Association of Dermatologists' guidelines for the management of squamous cell carcinoma in situ (Bowen's disease), British Journal of Dermatology, 170:245-260.

27. Mukaratirwa S, Chipunza J, Chitanga S (2005). Canine cutaneous neoplasms: prevalence and influence of age, sex and site on the presence and potential malignancy of cutaneous neoplasms in dogs from Zimbabwe. Journal of the South African Veterinary Association, 76:59-62.

28. Munday JS (2014). Papillomaviruses in felids, Veterinary Journal, 199:340-347.
29. Munday JS, French AF, Gibson IR, Knight CG (2013). The presence of $\mathrm{p} 16$ CDKN2A protein immunostaining within feline nasal planum squamous cell carcinomas is associated with an increased survival time and the presence of papillomaviral DNA. Veterinary Pathology, 50:269-273

30. Nespeca G, Grest P, Rosenkrantz WS (2006). Detection of novel papillomaviruslike sequences in paraffinembedded specimens of invasive and in situ squamous cell carcinomas from cats. American Journal of Veterinary Research, 67:2036-2041.

31. Nikula KJ, Benjamin SA, Angleton GM (1992). Ultraviolet radiation, solar dermatosis, and cutaneous neoplasia in beagle dogs. Radiation Research, 129:11-18.

32. Ruslander D, Kaser-Hotz B, Sardinas JC (1997). Cutaneous squamous cell carcinoma in cats. Compendium on Continuing Education for the Practising Veterinarian, 19:1119-1129.

33. Scott DW, Teixeira AC (1995). Multiple squamous cell carcinomas arising from multiple cutaneous follicular cysts in a dog. Veterinary Dermatology, 6:27-31.

34. Scott-Moncrieff JC, Elliot GS, Radvsky A, Blevins WE (1989). Pulmonary squamous cell carcinoma with multiple digital metastases in a cat, Journal of Small Animal Practice, 30: 696-699.

35. Silva-Hidalgo G, Juarez-Barrancao F, Lopez-Venezuela M, Davila-Peredes M (2015). Revista Cientifica Facultad de Ciencias Veterinarias, 25:304-310.

36. Teifke JP, Lohr CV, Shirasawa H (1998). Detection of canine oral papillomavirusDNA in canine oral squamous cell carcinomas and p53 overexpressing skin papillomas of the dog using the polymerase chain reaction and nonradioactive in situ hybridization. Veterinary Microbiology, 60:119-130.

37. Van der Linde-Sipman JS, van den Ingh TS (2011). Primary and metastatic carcinomas in the digits of cats, Veterinary Quarterly, 22(3): 141-145.

38. Van der Linde-Sipman JS, de Wit MM, van Garderen E (1997). Cutaneous malignant melanomas in 57 cats: identification of (amelanotic) signet-ring and balloon cell types and verification of their origin by immunohistochemistry, electron microscopy, and in situ hybridization. Veterinary Pathology, 34:31-38.

39. Van der Linde-Sipman JS, van den Ingh TS (2000). Primary and metastatic carcinomas in the digits of cats. Veterinary Quarterly, 22:141-145.

40. Withrow SJ, Vail DM (2007). Small Animal Clinical Oncology. ( $4^{\text {th }}$ ed). Saunders Elsevier. 